\title{
DETERMINANTES DE LA PERCEPCIÓN \\ DE CORRUPCIÓN LEGISLATIVA EN AMÉRICA LATINA \\ (1990-2016)
}

\author{
Determinants of legislative corruption perception \\ in Latin America (1990-2016)
}

\author{
ANA BELÉN BENITO SÁNCHEZ \\ Universidad Complutense de Madrid (UCM) \\ anabeben@ucm.es \\ ARACELI MATEOS DÍAZ \\ Universidad de Salamanca (USAL) \\ amd@usal.es \\ Cómo citar/Citation \\ Benito Sánchez, A. B. y Mateos Díaz, A. (2021). \\ Determinantes de la percepción de corrupción \\ legislativa en América Latina (1990-2016). \\ Revista de Estudios Políticos, 192, 221-252. \\ doi: https://doi.org/10.18042/cepc/rep.192.08
}

\section{Resumen}

Este trabajo identifica los cambios y continuidades en la percepción de la corrupción legislativa en América Latina en el periodo 1990-2016. A partir de los datos de opinión del proyecto "Varieties of Democracy» de la Universidad de Gotemburgo y el Instituto Kellogg, se explora el peso que podrían tener variables partidistas e institucionales sobre la percepción de la existencia de actividades ilícitas en los legislativos latinoamericanos. Los datos revelan que la ausencia de mecanismos de control y fiscalización ejercidos por el órgano legislativo y la jurisdicción ordinaria, la mercantilización de la movilización electoral y el peso de los intereses particularistas frente al bien común, son los factores que incrementan la probabilidad de percibir como corrupta la labor parlamentaria.

\section{Palabras clave}

Corrupción; legislaturas; percepciones de expertos; América Latina. 


\begin{abstract}
This work identifies changes and continuities in expert perceptions about legislative corruption in Latin America since democratic consolidation in 1990 to 2016. We use public opinion data from «Varieties of Democracy» project from Gothenburg University and Kellogg Institute, to explore the effect of partisan variables, and institutional variables, on the perception of legislative corruption in Latin America. Data shows that the lack of control by the legislative opposition and the ordinary courts, the commodification of electoral mobilization and the primacy of particularistic interests over the common good, are variables that increase the probability of perceiving parliamentary work as corrupt.
\end{abstract}

\title{
Keywords
}

Corruption; legislatures; expert's perceptions; Latin America. 


\section{SUMARIO}

I. INTRODUCCIÓN. II. MARCO TEÓRICO E HIPÓTESIS. III. DATOS Y MÉTODO. IV. RESULTADOS Y DISCUSIÓN: 1. Variable dependiente. 2. Variables independientes. 3. Análisis explicativo. IV. CONCLUSIONES. Biblografía. AneXos.

\section{INTRODUCCIÓN}

El Parlamento es el órgano de poder político más importante en democracia (Lijphart, 1991). Su función fiscalizadora convierte a los legislativos en actores clave para la gobernabilidad, ya que vigilan la eficacia de las políticas públicas y frenan los posibles abusos de poder. La fortaleza de estas competencias ha demostrado ser garantía del control entre poderes y estímulo para la construcción del sistema de partidos (Fish, 2006). Sin embargo, a pesar de ser numerosos los estudios acerca de las causas y consecuencias de la corrupción en el Ejecutivo (Rose-Ackerman, 1999; Treisman, 2000; Fisman y Gatti, 2002; Adsera, Boix y Payne, 2003; Kaufmann, 2005), poco sabemos de los factores que contribuyen a la percepción que diferentes actores tienen de la existencia y alcance de las actividades ilícitas con fines lucrativos en sede parlamentaria.

En este trabajo nos preguntamos por qué la corrupción legislativa en América Latina es percibida con mayor intensidad en unos países, mientras que en otros la dimensión del fenómeno no representa un rasgo distintivo. Utilizamos los datos de opinión de la encuesta de expertos «Varieties of Democracy» (V-Dem Project) con información acerca de la percepción de la frecuencia con la que los legisladores latinoamericanos transgreden la legalidad en el ejercicio de sus funciones en el periodo 1990-2016. Para ello, exploramos el peso que pudieran tener en dicha valoración elementos partidistas, de representación, receptividad de las políticas y la acción fiscalizadora de actores del entramado de control entre poderes. El análisis estadístico revela que la mercantilización de la movilización electoral, una débil oposición legislativa fiscalizadora, las decisiones políticas dominadas por intereses particularistas frente al bien común y la ausencia de independencia de las cortes ordinarias, son las variables que más influyen en la percepción de los expertos acerca de la corrupción en los Parlamentos latinoamericanos.

Con este propósito el artículo se estructura en cuatro apartados. En primer lugar, se hace un repaso a las principales aportaciones de la literatura y 
se plantean las hipótesis que sustentan la elección de las variables explicativas. En segundo lugar, se justifica el enfoque metodológico, la selección de los casos y la medición de los indicadores. Tras presentar los resultados, en el apartado de conclusiones se subrayan los hallazgos más relevantes acerca del impacto que pudieran tener las percepciones de corrupción en el seno de las legislaturas nacionales para la legitimidad y el ejercicio de las funciones de representación, normativas y de fiscalización.

\section{MARCO TEÓRICO E HIPÓTESIS}

La corrupción política es un mal uso del poder público encomendado con graves repercusiones sociales, económicas e institucionales. La percepción de corrupción y la constatación judicial de su existencia erosionan el capital social (Levi, 1996), frenan el desarrollo económico (Kaufmann, 2005) y cercenan la calidad de la democracia (Villoria, 2018). Teniendo en cuenta los rasgos que concitan mayor acuerdo en la literatura, puede ser entendida como el abuso de posición de un servidor público para conseguir un beneficio directo o indirecto, infringiendo las normas penales, administrativas o éticas que regulan el comportamiento de ese colectivo (Villoria y Jiménez, 2012).

En esta investigación sobre la percepción de corrupción en sede parlamentaria utilizamos la definición de Coppedge et al. (2018) para conceptualizar nuestra variable dependiente (VD) corrupción legislativa como el abuso de posición de los miembros del legislativo con fines lucrativos. La obtención de este lucro puede proceder de: a) aceptar sobornos en la gestión legislativa; b) ejercer de conseguidor de contratos públicos para sus propias empresas, las de amigos, de familiares o de aquellos que le apoyan políticamente; c) favorecer a empresas a cambio de oportunidades de empleo una vez que abandone la legislatura (puertas giratorias), y/o d) el uso personal del dinero público o de las donaciones recibidas en campaña (ibid.: 132). Por tanto, incluye desde el sesgo particularista de su función normativa con fines económicos o profesionales que desvirtúa el mandado general de representación, hasta el peculado en sentido estricto.

Para explicar por qué la corrupción legislativa es percibida en América Latina con mayor intensidad en unos países que en otros, analizamos el efecto de variables de naturaleza partidista, del tipo de representación, receptividad y control entre poderes cuyo efecto causal ha sido destacado por la literatura.

Con respecto a la dimensión partidista, exploramos el peso de cuatro decisiones de acción colectiva que han de adoptar los partidos: organización, financiamiento, democracia interna y disciplina. La literatura sobre la institucionalización de los sistemas de partidos ha destacado la importancia de la 
organización de la vida partidista en el éxito electoral y en la calidad de la democracia (Mainwaring y Scully, 1995; Morlino, 1995; Mainwaring y Torcal, 2005). Una infraestructura estable que dé soporte a la burocracia partidista facilita la rutinización de los protocolos y el reconocimiento de las reglas del juego interno (North, 1993). Las estructuras aseguran la continuidad del partido en periodos no electorales, generando compromisos sólidos con los valores aceptados por sus integrantes (Panebianco, 1997; Levitsky, 1998). Puesto que algunas de estas dependencias internas son las encargadas de vigilar el cumplimiento de los estatutos o el comportamiento ético de sus miembros como gestores públicos, esperamos encontrar relación entre estabilidad de la organización partidaria y menor percepción de corrupción legislativa. De esta manera, cuanto más estable sea la estructura organizativa de los partidos, menor será la probabilidad de que los legisladores abusen de su posición con fines lucrativos.

La segunda de las decisiones de acción colectiva que afecta al funcionamiento del partido es la financiación. Su existencia garantiza el fair play de la competición democrática y la independencia de los actores en la representación del interés general frente a la injerencia de mandatos particulares (Casas y Zovatto, 2011; Zovatto, 2017). El grado de imbricación del candidato en la búsqueda de recursos para la campaña permite distinguir partidos de «empresarios-políticos» —en los que el propio candidato ha de satisfacer sus necesidades financieras - frente a otros en los que el "partido nodriza» consigue los fondos y los distribuye de manera más o menos centralizada (Alcántara, 2004: 187). En América Latina predominan los sistemas mixtos de financiamiento, aunque con gran protagonismo de las donaciones privadas, por lo que la región pudiera ser un escenario propicio para el tipo de intercambios lucrativos como la concesión de contratos a empresarios que sufragaron la campaña del legislador. Por ello, esperamos encontrar relación entre financiamiento público y una menor percepción de corrupción en las legislaturas estudiadas. Una mayor relevancia del financiamiento público en la campaña de candidatos y partidos revertiría en una menor probabilidad de que los legisladores dependan de donaciones que hagan permeable el mandato de representación a las exigencias particularistas y corruptas de sus financiadores.

La forma en que se seleccionan los candidatos a cargos representativos es un indicador del nivel de democracia interna en las organizaciones (Rahat y Hazan, 2001; Payne et al., 2002; Martínez Rosón, 2011). Cuanto más plurales y participativos sean los métodos de selección, mayor será la transparencia (Sánchez Medero, 2018), la legitimidad (Ware, 1996) y el apego de los representantes a la voluntad de los electores. La democracia interna en los partidos políticos limita la oligarquización de sus cuadros (Freidenberg y Alcántara, 2009) y la corporativización de la representación (Langston, 2008; Wuhs, 
2010; Solís y Cortez, 2019) que se produce cuando los grupos de interés acceden al hemiciclo. Por ello, esperamos encontrar relación entre descentralización de la selección de candidatos a legislador y una menor percepción de corrupción en el ejercicio de sus actividades. Así, cuanto más descentralizada sea la designación de las candidaturas a legislador, menor será la tendencia de los legisladores a verse constreńidos por las exigencias corporativistas y clientelares de los líderes del partido para mantenerse en la vida pública.

La última de las decisiones de acción colectiva tiene que ver con la «imposición de la obediencia» (Ozbudun, 1970). La actuación conjunta de la bancada facilita la agregación de intereses, así como el éxito legislativo de sus iniciativas (Bowler et al., 1999; Sinclair, 2003). Con este propósito, los partidos establecen regímenes disciplinarios que aumenten el coste de las maniobras disidentes de los legisladores (Carey y Shugart, 1994; Owens, 2003). La actuación individualista pudiera estar motivada por un soborno para orientar la tramitación legislativa en contra de las preferencias programáticas compartidas, por lo que esperamos encontrar una menor percepción de corrupción cuando el partido habla como una sola voz colectiva en el Congreso. De esta manera, la existencia de cohesión legislativa y disciplina de la bancada repercutirá en una menor tendencia de los legisladores a involucrarse en actuaciones particularistas, instrumentales e ilegales.

Estos argumentos sobre el impacto de las cuatro decisiones de acción colectiva del partido sustentan la primera hipótesis de este trabajo:

Hipótesis partidista (H1). Cuanto mayor sea la institucionalización de la vida del partido como organización, menor será la percepción de corrupción legislativa.

Con respecto a la dimensión representación, estudiamos el peso de las decisiones de elección social que adoptan los partidos para configurar el nexo de unión con sus electores. Los sistemas de partidos programáticamente estructurados serían los únicos capaces de instaurar democracias plenas, ya que el vínculo programático es el que más se acerca al modelo de partido responsable y el que genera mayores niveles de gobernanza democrática (Kitschelt et al., 2010). Aunque el tipo de relación clientelar es uno de los posibles modelos de accountability en democracia, y no requiere de la ilegalidad para su existencia, ambos fenómenos tienden a viajar juntos, ya que para sufragar las costosas máquinas clientelares se suele acudir a los circuitos de la corrupción (Máiz, 2003). En nuestro análisis nos fijamos en la contingencia de los objetivos de acción política (oferta) y en los esfuerzos que realizan los partidos para que los ciudadanos acudan a las urnas (movilización), puesto que ambos aportan pistas sobre el particularismo (Kitschelt y Wilkinson, 2007; Otero y Rodríguez-Zepeda, 2015) y la mercantilización (Carlines y Love, 2015; 
Manzetti y Rosas, 2015) del mandato de representación, respectivamente. Respecto a la oferta, cuanto mayor sea la presencia de vínculos programáticos e ideológicos, menor será la probabilidad de que los parlamentarios opten por una estrategia de representación particularista que deban financiar mediante prácticas corruptas. Por su parte, desde el lado de la movilización, a una mayor compra de votos para incentivar la participación electoral, mayor será la probabilidad de que los legisladores abusen de su posición para recuperar la inversión que hicieron en su campaña:

Hipótesis representación (H2). Cuanto más contingente sea el nexo de unión de los parlamentarios con los electores, mayor será la percepción de corrupción legislativa.

La tercera de las dimensiones estudiadas tiene que ver con la receptividad de las políticas a los intereses de la ciudadanía. La agregación de intereses en las instituciones públicas se lleva a cabo a través del diálogo razonado sumando preferencias divergentes e incluyendo otras nuevas compartidas por los ciudadanos (March y Olsen, 1984). De esta manera, en el hemiciclo se generan aspiraciones colectivas que han de ser satisfechas por los representantes, a quienes los electores han delegado la formulación de las políticas. Si bien la ley debe ser expresión de la voluntad general, diversos autores han demostrado que el proceso legislativo puede verse capturado por actuaciones extractivistas (Acemoglu y Robinson, 2012) y oportunistas (Krehbiel, 2004) que distorsionan la promoción del interés general. En este sentido, esperamos encontrar una relación positiva entre justificación de las decisiones normativas en términos de promoción del bien común, y una menor percepción de corrupción acerca de la actuación de los legisladores como conseguidores y patrocinadores de tales intereses. Cuanto más se justifiquen los cambios normativos en la protección del bien común, menor será la probabilidad de que estos respondan a los intereses extractivistas y oportunistas de lobbies y grupos empresariales:

Hipótesis responsiveness (H3). Una mayor receptividad de los políticos a los intereses generales en el diseño de políticas influirá en una menor percepción de corrupción legislativa.

En la última de las dimensiones medimos el peso de la fiscalización que llevan a cabo diversos actores. El primero es el propio órgano legislativo, que dispone de instrumentos como el juicio político, las comparecencias e interpelaciones a altos cargos del Gobierno, la Administración y el Legislativo, las demandas de información al Ejecutivo o la creación de comisiones de 
investigación. A pesar del papel marginal de los Parlamentos en el presidencialismo (Cox et al., 2001), diversos estudios han destacado la importancia de los incentivos partidistas a la hora de explicar el papel reactivo o proactivo de las legislaturas, tanto en sus funciones normativas (García Montero, 2009) como en las de supervisión (Gutmann et al., 2015). Estos autores demuestran que la presencia de otras fuerzas en el hemiciclo influye en el ejercicio de la potestad fiscalizadora, ya que la mayor competencia política incentivaría descubrir y difundir la corrupción de los oponentes. Por lo tanto, en un contexto institucional diverso - que va del diseño presidencialista puro en países como México y Brasil, con matices parlamentarios en Uruguay y Bolivia, o de presidencialismo parlamentarizado en Argentina y Colombia - esperamos encontrar relación entre el ejercicio de supervisión e investigación de la oposición y una menor percepción de corrupción. Así, cuanto mayor sea la actividad fiscalizadora y proactiva de los legisladores de la oposición, menor será la probabilidad de que los legisladores oficialistas lleven a cabo actividades corruptas durante su mandato.

El segundo de los actores del control entre poderes es la Administración pública, encargada de hacer posible la acción de gobierno a través de sus recursos humanos y medios materiales. La actividad administrativa está sometida al principio de legalidad que rige el Estado de derecho, sirviendo a los intereses generales con imparcialidad y neutralidad. Numerosos estudios sobre los procesos de burocratización en democracias emergentes han demostrado la correlación entre profesionalización de la gestión administrativa y la corrupción (Rauch y Evans, 2000; Papakostas, 2001; Neshkova y Kostadinova, 2012; Oliveros y Schuster, 2018). A pesar de las reformas de las últimas décadas, la discrecionalidad en la selección del funcionariado y los vínculos de lealtad al líder siguen caracterizando la gestión de muchas de las burocracias latinoamericanas (Ferraro, 2009; Moriconi, 2011). Puesto que los legisladores pudieran necesitar de un cómplice y/o ejecutor funcionario para llevar a cabo sus actividades corruptas, esperamos encontrar un menor apoyo administrativo a las actividades corruptas de los legisladores cuanto mayor sea el grado de profesionalización de la Administración.

Los organismos electorales son el tercer actor fiscalizador considerado en este trabajo. La creación de estos entes especializados y autónomos ha jugado un papel importante en la consolidación democrática en América Latina, ya que han contribuido a reducir el fraude electoral y generado confianza pública (Barreda y Ruiz, 2014). Los trabajos de Picado (2006), Barrientos (2010) y Thompson (2014) muestran que cuanto mayor es la injerencia de partidos y Gobiernos en la selección de las autoridades electorales, menor es su autonomía, por lo que es factible una relación entre imparcialidad de la administración electoral y percepción de corrupción en las legislaturas latinoamericanas. 
Cuanto mayor sea la autonomía e imparcialidad del órgano electoral en la fiscalización de las elecciones, partidos y candidatos, menor será la probabilidad de que los representantes incurran en actividades ilícitas.

Por último, estudiamos el papel fiscalizador del poder judicial como garante del Estado de derecho. Los tribunales son los encargados de vigilar con imparcialidad e independencia al Ejecutivo y su sometimiento al imperio de la ley. En América Latina, muchos de sus Gobiernos han tratado de utilizar las reformas legales para tomar el control de la judicatura, impidiendo la consolidación de la independencia judicial (Martínez Barahona, 2010; Pérez Liñán, 2011). La politización de la justicia dificulta que los jueces ordinarios resuelvan los casos «sin temores ni favores» (Van Zyl, 2016: 40), y genera un escenario de impunidad favorable a la corrupción de los representantes del partido oficialista de turno. Por ello, se plantea una relación entre independencia judicial y una menor percepción de corrupción legislativa. La independencia judicial respecto de las presiones del Gobierno influirá positivamente en que se persigan los actos de corrupción cometidos por los legisladores.

A partir de estos argumentos sobre la efectividad de la accountablity horizontal como control rutinario para prevenir, cancelar, reparar y castigar acciones de otra agencia estatal (O’Donnel, 2004: 12) esperamos encontrar una relación positiva entre la independencia de los agentes fiscalizadores y una menor percepción de actos ilícitos en sede parlamentaria:

Hipótesis accountability (H4). Cuanto mayor sea la independencia de la relación de control entre poderes, menor será la percepción de corrupción legislativa.

\section{DATOS Y MÉTODO}

Para comprobar el peso de las variables que inciden en la percepción de una mayor o menor actividad ilícita en los Parlamentos latinoamericanos, utilizamos la encuesta de expertos V-Dem Project de la Universidad de Gotemburgo y el Instituto Kellogg. Esta encuesta se realiza a expertos nacionales, cuenta con cuatrocientos cincuenta indicadores sobre la dimensión electoral, participativa, deliberativa, liberal e igualitaria de la democracia en doscientos países desde el pasado siglo hasta el año 2017, y posee ciertas ventajas frente a otras encuestas también de carácter individual focalizadas en la ciudadanía, tal como exponemos a continuación.

Los sondeos de opinión utilizados para capturar la percepción de corrupción han permitido acercarse empíricamente a este fenómeno de difícil medición, generando índices y rankings como el de Transparencia Internacional (Transparency International, 2018) o el del Banco Mundial (World Bank, 
2017), de gran utilidad para investigadores y encargados de formular políticas. A pesar de ello, se ha cuestionado la naturaleza agregada de sus datos, la estandarización de conceptos que pudieran tener distintas acepciones según el contexto cultural (Weber, 2008), la variedad de unidades de información de los indicadores y la forma en que se construyen los índices. Para los más críticos, los índices elaborados con percepciones subjetivas no estarían capturando la frecuencia con la que se suceden las actividades corruptas, sino que representarían meras inferencias que los expertos hilan en base a ideas convencionales acerca de las causas de la corrupción (Treisman, 2007: 13). Al mismo tiempo, mientras que las encuestas de victimización por corrupción muestran correlación fundamentalmente con el nivel de desarrollo, las basadas en corrupción percibida lo hacen con una variedad de factores como son el desarrollo económico, la experiencia democrática, libertad de prensa, presencia de mujeres en el Gobierno y la tradición de apertura comercial (Treisman, 2007: 11). Estas divergencias podrían deberse a sesgos de optimismo, al efecto de los ciclos económicos en los casos seleccionados o la disponibilidad de información (Gutmann et al., 2015).

Por otro lado, los indicadores basados en la corrupción que empresarios y ciudadanos han experimentado en su interacción con diferentes ámbitos de la Administración ofrecen una fotografía de enfoque micro que no captura la que tiene lugar en los más altos niveles del Estado, ni la extensión del fenómeno en el escenario nacional. No obstante, aunque las encuestas de expertos adolecen de un cierto sesgo derivado del mayor acceso a fuentes de información y del nivel de conocimiento que poseen en sus respectivos campos -analizando la corrupción en términos de proceso frente al acercamiento más casuístico del ciudadano-, en la medida en que influyen en la toma de decisiones de agentes estatales y empresariales representan una unidad de información confiable acerca de la dimensión y pervivencia del fenómeno (Mauro, 1995).

De los cuatrocientos cincuenta indicadores de la base de datos V-Dem, para este análisis se han seleccionado aquellos relevantes para nuestro objeto de estudio en dieciocho países de la región latinoamericana, desde 1990 - fecha en que tienen lugar los procesos de transición y consolidación democrática en la mayoría de ellos- hasta el año $2016^{1}$. Las unidades de análisis

El año de observación de la primera legislatura es 1989 para Argentina, Bolivia, Chile, Panamá, Paraguay, Uruguay, Venezuela; 1990 para Brasil, Colombia, Costa Rica, Dominicana, Ecuador, Honduras, Nicaragua, Perú, y 1991 para Guatemala, México, El Salvador. El último año de observación 2016 coincide con el fin de legislatura en Dominicana, Nicaragua y Perú. En el resto la legislatura finaliza en 2018, 2019 y 
son las legislaturas nacionales y puesto que la información en la base de datos está recopilada por año, se ha calculado la media de los valores de las variables seleccionadas para obtener un único valor por legislatura. En aquellas variables con ausencia de información se ha llevado a cabo una imputación del valor teniendo en cuenta el resto de los valores que presentaba la variable en los años más próximos en dicha legislatura o en los de la legislatura más próxima $^{2}$. El hecho de considerar cada país-legislatura como casos independientes permite incrementar el número de casos de nuestro estudio, además de revisar el efecto de cambios institucionales y socioeconómicos que hayan tenido lugar y que pueden variar más de legislatura en legislatura que entre países. Como resultado, nuestra base de datos regional está formada por ciento treinta casos ubicados en un escenario temporal de veintiséis años, y por once indicadores ${ }^{3}$ representativos de las posibles explicaciones de la corrupción legislativa ${ }^{4}$.

Dado que la duración de los mandatos legislativos difiere entre países, el número de observaciones/país varía entre las doce de Argentina, con el mayor número de casos, y las cinco de Nicaragua, con el menor número 5 . Sin embargo, el análisis no busca una lógica o explicación por país, sino valorar el efecto de las variables en el conjunto de casos, de manera que no se ha realizado ningún tratamiento o ponderación de los mismos en función del mayor o menor número de legislaturas por país sobre el total.

La variable dependiente (VD) definida en la encuesta V-Dem como los abusos de posición de los miembros de la legislatura con fines lucrativos,

2020. No existen datos de acceso público para estos ańos, por lo que se calcula la media según los años disponibles.

2 Por lo que se refiere a la variable compra de votos, su información se refiere al momento en que se celebran las elecciones, es decir, dentro del primer año de cada legislatura estudiada, de manera que, al no existir información para el resto de años de la legislatura, el valor para el periodo está referido a un único momento.

3 Se es consciente de la discrepancia entre el número de casos y el de variables. Se opta por este tipo de análisis dada la complejidad explicativa del fenómeno estudiado y por tratarse de democracias no muy longevas donde el número de casos es limitado.

4 En el anexo se encuentra la formulación de las preguntas y categorías de respuesta para cada uno de los indicadores explicativos utilizados. La formulación se acompaña de una explicación para que los expertos se guíen por los mismos criterios y garantizar la fiabilidad. Todas las variables han sido medidas de forma ordinal. Disponible en: https://www.v-dem.net/en/analysis/.

5 Argentina (12); Bolivia (7); Brasil (7); Chile (7); Colombia (7); Costa Rica (7); Dominicana (6); Ecuador (9); Guatemala (7); Honduras (7); México (9); Nicaragua (5); Panamá (6); Perú (6); Paraguay (6); El Salvador (9); Uruguay (6); Venezuela (7). 
presenta una distribución con ausencia de casos en la categoría de respuesta «habitualmente» $y$ una cantidad reducida en la de «nunca o casi nunca» $(4,6 \%$ de la distribución de los casos). Por ello, para su análisis descriptivo se ha recodificado la VD de cinco categorías a tres: «frecuentemente», «algunas veces» $y$ «muy ocasionalmente nunca». Para el análisis explicativo esta ha sido dicotomizada contrastando los casos en los que las actividades ilícitas tienen lugar frecuentemente frente al resto de situaciones.

En el siguiente apartado presentamos el diagnóstico descriptivo del grado de corrupción percibida por los expertos en cada país y legislatura, así como un análisis de regresión ${ }^{6}$ que permite comprobar el efecto diferencial que tienen las variables institucionales y partidistas sobre dicha percepción en los Parlamentos de la región.

\section{RESULTADOS Y DISCUSIÓN}

\section{VARIABLE DEPENDIENTE}

¿Con qué frecuencia los miembros de la legislatura están envueltos en la concesión de contratos para sus empresas, las de sus familiares o de quienes les apoyen políticamente, aceptan sobornos en la tramitación legislativa o se apropian de dinero público o privado recibido? La distribución de las valoraciones de los expertos (tabla 1) muestra que en estos veintiséis años (19902016), los representantes latinoamericanos han utilizado frecuentemente su posición con fines lucrativos en más de la mitad de las legislaturas (56,9\%). En el 32,3\% de ellas este tipo de actividades fueron percibidas como ocasionales, y en el 10,8\% restante ha sido un fenómeno esporádico o inexistente.

\section{Tabla 1. Percepción actividades corruptas}

en las legislaturas latinoamericanas 1990-2016

\begin{tabular}{lcccc}
\hline \multicolumn{5}{c}{ ¿Los miembros de la legislatura abusan de su posición con fines lucrativos? } \\
\hline & Frecuentemente & Algunas veces & Muy ocasionalmente, nunca & Total \\
\hline $\begin{array}{l}\text { Total } \\
\text { (\% filas) }\end{array}$ & 74 & 42 & 14 & 130 \\
\hline
\end{tabular}

Fuente: elaboración propia con datos de V-Dem Project Dataset $v 8$

6 Para su análisis explicativo la variable dependiente se ha recodificado en dos valores, discriminando la categoría «frecuentemente» frente al resto de opciones. 


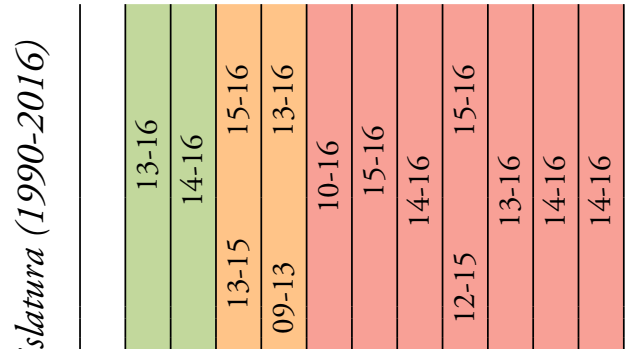

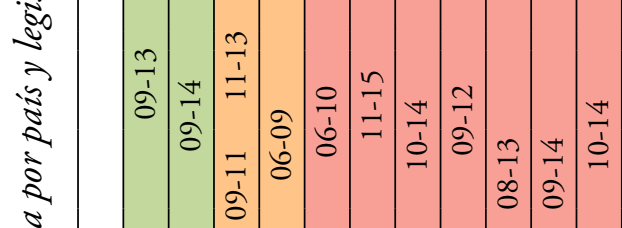

2

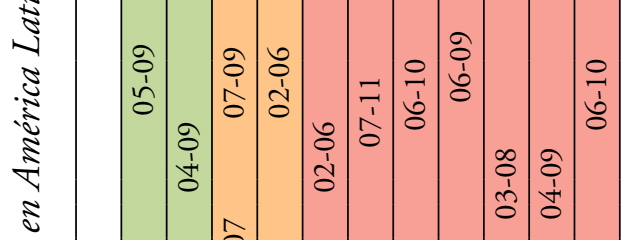

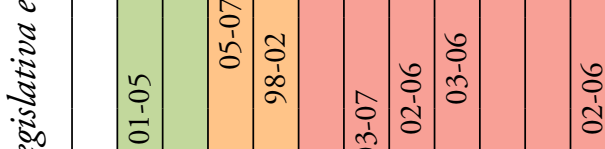

胥

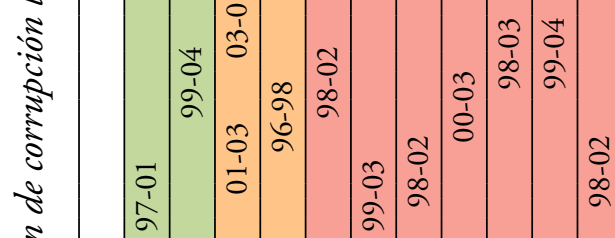

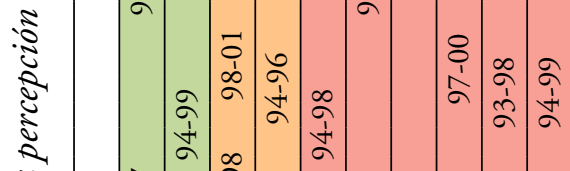

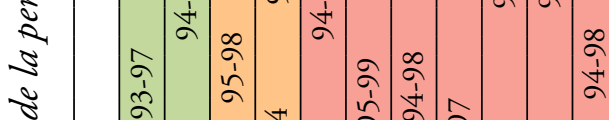

है है

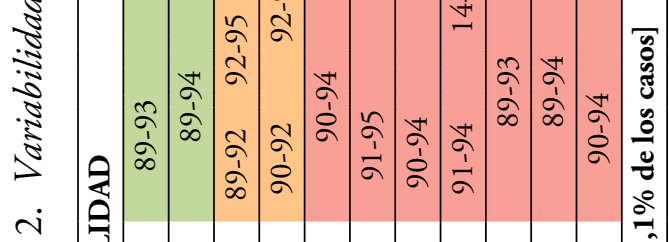

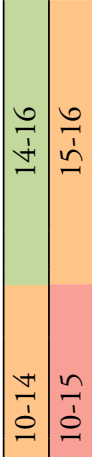

$=$

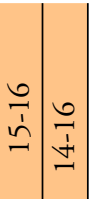

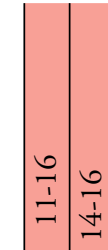

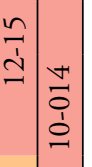

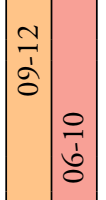

$\underset{\substack{1 \\ 0}}{0}$

ôे

चे

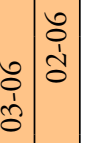

$\begin{array}{cc}0 & \\ \vdots & 8 \\ & 1 \\ 0 & 0\end{array}$

을

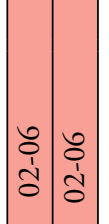

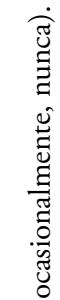

完

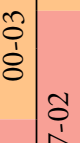

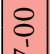

文

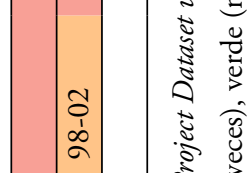

ชิ

ầ

๙à

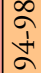

$\infty$ गิ

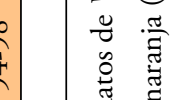

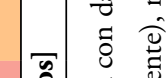

. ํㅐㄹ

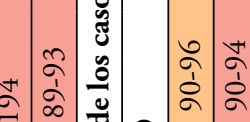

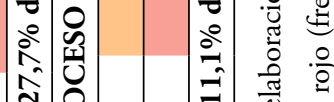

$\frac{a}{c}$

:

กิบ

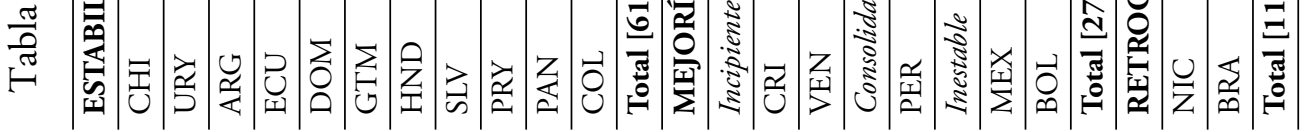


La fotografía longitudinal desagregada por país de la tabla 2 permite identificar los cambios y continuidades en la percepción de la corrupción legislativa por país en las dos últimas décadas.

Para once países de la región se trata de una fotografía estática, con más de veinticinco años sin cambios en la percepción sobre la frecuencia de actividades corruptas, aunque con diferentes intensidades. Entre ellos destacan Chile y Uruguay como Parlamentos libres de sospecha desde el punto de vista de los expertos. Argentina y Ecuador son ejemplos de Parlamentos donde las ilegalidades se estiman esporádicas, y otro grupo de siete países donde la corrupción es percibida como un fenómeno frecuente desde el inicio de la consolidación democrática hasta el año 2016. Este grupo de países con todas las legislaturas ubicadas por los expertos en el «semáforo rojo» de la corrupción está formado por Guatemala, Honduras, El Salvador, República Dominicana, Paraguay, Colombia y Panamá.

A esta percepción han podido contribuir ejemplos de relevancia pública que muestran la variedad de mecanismos para la obtención del lucro como en Guatemala, donde el presidente del Congreso y 168 legisladores fueron investigados en 2013 por tráfico de influencias y sustracción de fondos públicos en una trama de nóminas falsas que comprometió el $64 \%$ del presupuesto anual del organismo ${ }^{7}$. En 2003, el presidente de la Cámara de Representantes de Colombia fue condenado a doce ańos de prisión por urdir un plan de reparto de contratos entre los miembros de la mesa directiva durante su gestión ${ }^{8}$. O el caso de la República Dominicana, donde la constructora Odebrecht habría utilizado desde el año 2007 los servicios de un intermediario lobista encargado de pagar a los legisladores e influir en la adjudicación de contratos y aprobación de los préstamos en el Congreso para la realización de sus obras?.

En los siete países restantes encontramos variaciones de sentido e intensidad en la percepción de actividades corruptas en sede parlamentaria. Los expertos aprecian hasta 2016 una mejora incipiente en Venezuela y Costa Rica. Ambos países han experimentado hasta esa fecha un cambio de tendencia que rompe con la estabilidad en la valoración de la corrupción de los periodos asamblearios pasados. Estas legislaturas percibidas como menos corruptas comparten un menor peso del oficialismo en la composición de las mismas,

7 Véase: «El Congreso de Guatemala, investigado por corrupción», El País, 28-01-2016, disponible en: https://bit.ly/33wqtfK.

8 Véase: «12 años de cárcel para Pomárico», El Tiempo, 25-09-2003, disponible en: https://bit.ly/3tws0wV.

9 Véase: «El hombre del maletín», Listín Diario, 1-06-2017, disponible en: https://bit. ly/3heR611. 
pudiendo ser tal circunstancia el espacio de oportunidad para el ejercicio fiscalizador de la oposición. En el caso de Venezuela, el triunfo de la Mesa de Unidad Democrática (MUD) en 2015 puso fin a diecisiete años de chavismo en la Asamblea Nacional, mientras que en Costa Rica la primera fuerza de la oposición, el Partido Acción Ciudadana (PAC), ajena al tradicional binomio calderonismo-liberacionismo, se consolida en 2014 como partido de gobierno y pasa a engrosar junto a Chile y Uruguay la lista de países libres de corrupción legislativa en opinión de los expertos consultados.

Perú es un caso de mejora consolidada, ya que las tres últimas legislaturas confirman el cambio de tendencia en la percepción de corrupción en el seno de esta cámara, que coincide con el fin de los gobiernos de Alberto Fujimori en 2001. En las elecciones fraudulentas del año 2000 tuvo lugar el soborno a los dieciocho diputados opositores gracias a los cuales el fujimorismo construyó su mayoría ilegítima ${ }^{10}$. El escándalo de los tránsfugas escenifica en el Legislativo la red de corrupción urdida en todos los poderes del Estado y las violaciones de derechos humanos cometidas para perpetuarse en el poder desde el autogolpe de 1992. Tras su huida a Japón, el propio Congreso de la República declaró a Fujimori moralmente incapacitado para desempeñar cualquier función pública.

Bolivia y México muestran a lo largo de estos veinticinco años una mejoría inestable, alternando etapas de mayor y menor percepción de actividades corruptas en sus Parlamentos. En este último, el fin del predominio en el Congreso del Partido Revolucionario Institucional (PRI) en el 2000 da paso a cuatro legislaturas consecutivas con una mejor valoración que la otorgada a las de la década anterior. Una de las corruptelas más habituales entre los legisladores mexicanos recibe el nombre de "moche», y consiste en la ejecución directa de partidas federales destinadas a programas sociales, pero utilizadas en su circunscripción en forma de obras para premiar la complicidad proselitista de empresarios amigos ${ }^{11}$. El deterioro en la evaluación de la legislatura 2012$2015^{12}$ se recupera en la siguiente, en un patrón secuencial similar al caso boliviano.

Nicaragua y Brasil muestran, por el contrario, una fotografía de retroceso en la valoración de la corrupción legislativa con respecto a la década de los noventa. En el caso de Nicaragua, las elecciones fundacionales de 1990 ponen

10 Véase: «Fujimori consigue mayoría en el Congreso gracias a diputados tránsfugas», $E l$ Pais, 27-07-2000, disponible en: https://bit.ly/3tws6Vj.

11 Véase: «Los moches», en Proceso, 9-06-2018, disponible en: https://cutt.ly/RvaDLen.

12 En estos ańos tienen lugar las detenciones por corrupción de dos conocidos legisladores y dirigentes sindicales del sector petrolero (STPRM) y de la enseñanza (SNTE). 
fin al proceso revolucionario y la guerra de la contra. Esta legislatura será la única del periodo estudiado con menor percepción de actividades legislativas corruptas. A partir del Pacto Ortega-Alemán de 1996, se observa un deterioro en las valoraciones de los expertos con respecto a la Asamblea Nacional en el marco de un patrimonialismo autoritario que se prolonga hasta la fecha (Martí, 2018: 321). En Brasil, a partir del año 2002 aumenta la frecuencia de actividades ilícitas de los legisladores según las valoraciones de los entrevistados ${ }^{13}$. Hasta el año 2016 se descubren algunos de los escándalos más mediáticos por su dimensión regional e implicaciones políticas como «Lava Jato» Petrobras y Odebrecht ${ }^{14}$, en los que medio centenar de diputados federales y senadores se vieron envueltos en una trama de sobornos y corrupción petrolera ${ }^{15}$.

\section{VARIABLES INDEPENDIENTES}

Tal y como muestra la literatura, existen variables de naturaleza partidista, del tipo de representación, receptividad y control entre poderes, que incrementan o reducen la probabilidad de que se den actividades corruptas en el Legislativo. Por ello, en este trabajo se han incorporado como variables independientes indicadores de todas ellas que presentan países-legislaturas con heterogeneidad en sus modelos de organización partidista, de financiación de sus campañas, selección de candidatos, variedad en el tipo de cohesión partidista, en las formas de movilización electoral, inclusividad de las políticas públicas y de entramados de accountability. La descripción, recodificación y distribución de las variables explicativas se presenta en el anexo. Todas ellas — salvo la selección de candidatos por su carácter más categórico- han sido dicotomizadas para su incorporación en la regresión logística. Dicha recodificación ha estado guiada por las expectativas de las hipótesis de trabajo.

\section{ANÁLISIS EXPLICATIVO}

¿Por qué el abuso de posición con fines lucrativos por parte de los miembros de la legislatura es percibido con mayor intensidad en unos países que en

13 En la legislatura 1990-1994 tiene lugar el impeachment contra el presidente Collor de Mello por corrupción. Fue absuelto por el Supremo Federal en 2014 por falta de pruebas. En 2006 fue electo senador y desde el 2015 imputado en la operación Lava Jato.

14 En 2017 el expresidente Lula da Silva es condenado por corrupción pasiva. En agosto de 2016 el Senado inicio un impeachment contra la presidenta Dilma Rousseff por alteración de las cuentas públicas que se saldó con su destitución.

15 Véase «Cronología de la operación Lava Jato», en El País, 12-04-2017, disponible en: https://bit.ly/3heXHs1. 
otros? ¿Qué factores de naturaleza partidista, tipo de representación, responsiveneness y accountability explican la percepción de corrupción en los Parlamentos de América Latina? Como se ha comentado previamente, para responder a esta pregunta se ha realizado una regresión logística donde la variable dependiente ha sido dicotomizada en dos categorías: (1) «Frecuentemente» y (0) «Resto», para contrastar cuándo los expertos valoran que las actividades corruptas en sede legislativa se producen de manera frecuente, frente a aquellos países donde se producen en menor medida.

El modelo presentado en la tabla 3 permite extraer un primer diagnóstico, y es que ninguna de las variables partidistas consideradas incrementa o disminuye la probabilidad de corrupción legislativa, frente a otras variables asociadas a la rendición de cuentas, el tipo de representación o la receptividad de las políticas, que sí tienen un efecto sobre ella.

Del conjunto de variables utilizadas en este trabajo, cuatro tienen una relación importante con la percepción de corrupción legislativa. En primer lugar destacan aquellas que tienen que ver con el control entre poderes. Cuando los partidos de oposición con representación legislativa son capaces de ejercer funciones de fiscalización e investigación con regularidad, la probabilidad de que existan actividades ilegales en sede parlamentaria es nueve veces menor que en aquellos países donde los partidos de oposición no las ejercen o solo de manera ocasional. Por lo que se refiere al control ejercido por el poder judicial, en los países y legislaturas en los que las cortes ordinarias nunca o casi nunca actúan con independencia frente al Gobierno de turno, es cinco veces más frecuente que se perciba que hay corrupción legislativa que en aquellos en los que siempre, habitualmente o la mitad del tiempo, las cortes ordinarias realizan su trabajo con plenas garantías de independencia.

La variable utilizada para medir la receptividad de la política al interés general frente a intereses particularistas de grupos empresariales y lobbies, también presenta asociación con la identificación por parte de los expertos de prácticas corruptas en el Legislativo. Cuando las élites políticas siempre o casi siempre justifican sus posiciones o los cambios normativos importantes para promover el bien común, la probabilidad de que se den actividades corruptas en el Legislativo es cinco veces menor que en aquellos casos en los que los intereses de determinados grupos, electorados, partido o intereses geográficos justifican su toma de decisión.

Por su parte, el tipo de representación política, medida a partir de la existencia o no de compra de votos en las elecciones nacionales, también está relacionada con la presencia de corrupción legislativa. La probabilidad de que las actividades ilícitas en el legislativo sean frecuentes, es cuatro veces menor en aquellos países y legislaturas donde no exista un escenario en el que se compren votos con dinero, bienes o promesas de empleo durante la campańa electoral. 
Tabla 3. Regresión logistica de los determinantes de la percepción de corrupción legislativa en América Latina

\begin{tabular}{lcc}
\hline & B & Exp (B) \\
\hline Organización partidista: Permanente (1) &,- 697 &, 498 \\
\hline Financiación de la campańa: Pública (1) &,- 223 &, 800 \\
\hline Selección candidatos: & & \\
\hline Líderes + organizaciones estatales y locales (0) &, 128 & 1,137 \\
\hline Diferentes niveles organizativos (1) &, 880 & 2,412 \\
\hline Organizaciones locales y actores municipales (2) &,- 382 &, 682 \\
\hline Cohesión partidista legislativa: Siempre (1) &, 308 & 1,361 \\
\hline Vínculos con el electorado: Programáticos (1) & $-1,480^{*}$ &, 228 \\
\hline Compra de votos: Ausencia (1) & $-1,595^{*}$ &, 203 \\
\hline Receptividad: Bien común (1) & $-2,225^{* *}$ &, 108 \\
\hline Oposición legislativa fiscalizadora: Si (1) & $-1,261$ &, 283 \\
\hline Profesionalización de la Administración: Respetada (1) & $-1,210$ &, 298 \\
\hline Capacidad fiscalizadora órgano electoral: Sí (1) & $1,618^{*}$ & 5,041 \\
\hline Independencia cortes ordinarias: Nunca (1) & 3,462 & 31,885 \\
\hline Constante & $85,4 \%$ & $(130)$ \\
\hline \% casos predichos correctamente (N) & & \\
\hline
\end{tabular}

" $\mathrm{p}<0,05,{ }^{* *} \mathrm{p}<0,01,{ }^{* * *} \mathrm{p}<0,001$.

R cuadrado de Nagelkerke $=, 605$.

Fuente: elaboración propia con datos de V-Dem Project Dataset v8.

Por tanto, la estrategia utilizada para captar el voto y la prioridad del bien común en la toma de decisión política determinarían la percepción de una mayor o menor presencia de actividades corruptas en los Parlamentos latinoamericanos, junto a mecanismos de control y fiscalización ejercidos por el propio órgano legislativo y las cortes ordinarias.

Los resultados de este análisis ponen de manifiesto que las variables de contenido partidista y algunas relacionadas con la rendición de cuentas entre poderes no tienen ningún efecto sobre la percepción de corrupción. Esto significa que sistemas de partidos más o menos cohesionados en los que la selección de los candidatos esté más o menos controlada por el partido 
político, cuente o no con una estructura organizativa más o menos permanente, o el tipo de financiación, no influye en la percepción de una mayor actividad legislativa ilícita. De la misma forma, el tipo de vínculo con el electorado (clientelar, localista o programático), la autonomía del órgano electoral con respecto a los intereses del Gobierno en el ejercicio de su capacidad fiscalizadora, y la profesionalización de la Administración tampoco determinan la frecuencia de las actividades instrumentales e ilegales de los legisladores durante su mandato.

El repaso a estos condicionantes en dos de los países con la mayor y menor frecuencia de corrupción legislativa percibida (República Dominicana y Uruguay) delimita en los extremos el heterogéneo escenario de fórmulas posibles de institucionalización partidista, representación política y rendición de cuentas en la región. Los datos de opinión del Proyecto Élites Parlamentarias Latinoamericanas (PELA) muestran que en la República Dominicana — caso de estabilidad corrupta con todas las legislaturas en el semáforo rojo de la percepción de corrupción durante veintiséis años- el $85 \%$ de los diputados entrevistados reconocieron entregar bienes, dinero y otras prebendas como incentivo para conquistar el voto, frente al escaso $10 \%$ de los diputados en Uruguay, donde estas prácticas fueron percibidas como un fenómeno esporádico o inexistente (Alcántara,1994-2017).

$\mathrm{La}$ independencia de las Cortes ordinarias en ambos países revela grandes diferencias. Uruguay ocupaba en 2016 el puesto 21 — primero de la región latinoamericana - en el Ranking de Independencia Judicial elaborado por el Foro Económico Global, por encima de países de la OCDE como Alemania y Austria, que ocupaban la posición 24 y 26 respectivamente (WEF, 2016). Por el contrario, la valoración de la independencia del sistema judicial frente al Gobierno o la presión de individuos y corporaciones situaba a la República Dominicana en el puesto 127 del total de los 138 países considerados, posición esta última ocupada por la vecina Venezuela. El papel fiscalizador del Legislativo también encuentra un escenario más propicio en el presidencialismo parlamentarizado de este país del Cono Sur, que en el presidencialismo dominicano de tipo dominante, donde la Cámara de Diputados tiene un papel marginal y distributivo (Benito, 2017: 173).

En relación con la justificación de las decisiones normativas importantes, algunos datos sobre el poder de las élites para capturar el Estado a través de exoneraciones, la socialización de costes privados y políticas fiscales favorables, ilustran el desigual peso de los intereses particularistas en las decisiones de política pública que promueven el bien común. Mientras que la carga tributaria de Uruguay es la más alta de América Latina y alcanza el 35\%, la República Dominicana apenas recauda el $14 \%$ del PIB. En este país se estima que los incentivos al turismo representan hasta el $84 \%$ del valor de las empresas 
del sector (Cañete Alonso, 2015: 65). En el caso de la sanidad, el modelo dominicano de gestión privada de fondos públicos y copago ha provocado un aumento del $60 \%$ de los gastos de bolsillo en tan solo cinco años (ibid.: 81). Un escenario que difiere del incremento que ha experimentado desde 2005 el presupuesto en salud en Uruguay, donde el gasto privado ha pasado del 49,2\% en 2003 al 36,9\% en 2008 (MSP, 2011).

\section{CONCLUSIONES}

¿Abusan los parlamentarios latinoamericanos del poder público encomendado? Los datos de percepción de corrupción legislativa de la encuesta «Varieties of Democracy» reflejan que en más de la mitad de las legislaturas del periodo estudiado los expertos consideran que los representantes habrían utilizado frecuentemente su posición con fines lucrativos (56,9\%). Con respecto a la variabilidad identificada por los especialistas nacionales, en once países de la región no ha habido cambio alguno en la intensidad percibida a lo largo de los años analizados: legislaturas libres de indicadores de corrupción legislativa en Chile y Uruguay; percepción de actividades corruptas ocasionales en Argentina y Ecuador; y el grupo más numeroso en el semáforo rojo de la percepción de corrupción, en el que se encontrarían países como República Dominicana o Guatemala. Para los siete países restantes se encuentran variaciones de intensidad que van desde la mejoría consolidada de Perú, la incipiente de Costa Rica o la más inestable de Bolivia. Los indicadores de Nicaragua y Brasil muestran una fotografía de retroceso en la valoración negativa realizada por los expertos con respecto a la década de los noventa.

En la identificación de las variables que explican por qué el abuso de poder de los legisladores es percibido en América Latina con mayor intensidad en unos países que en otros, este trabajo revela que diferentes tipos de decisiones de acción colectiva e institucionalización partidista no incrementan ni disminuyen la frecuencia con la que son identificadas las actividades corruptas en el Legislativo. Por tanto, la menor percepción de corrupción parlamentaria puede darse tanto en escenarios organizativos menos institucionalizados como los partidos máquina, con mecanismos de selección de candidatos en los que no participan las bases, y con poca disciplina en su accionar parlamentario.

Sí tiene efecto una de las variables de representación política: la mercantilización selectiva de la movilización. El análisis revela que cuanto más prebendalista sea la movilización de los electores, mayor será la probabilidad de señalar que los legisladores utilizan su cargo para recuperar la inversión que hicieron en campaña. La justificación de las decisiones normativas importantes, en términos de protección del bien común o receptividad de las 
políticas frente a intereses extractivistas y oportunistas, también está asociada con una mayor o menor percepción de abuso de la posición de los legisladores en sus tareas normativas.

Los actores del entramado del control de poderes con mayor peso a la hora de limitar la percepción de actividades corruptas son el propio órgano legislativo en sus labores fiscalizadoras (comisiones de investigación, interpelaciones, comparecencias, etc.) y los tribunales ordinarios. Por el contrario, el control ex ante del órgano electoral y el cumplimiento de los funcionarios en su papel de cómplices necesarios o agentes inhibidores de las intenciones corruptas de los diputados no tienen peso en este modelo.

La percepción de corrupción legislativa, medida en este trabajo a partir de la imagen que tienen los expertos nacionales, cercena la credibilidad ciudadana en la institucionalidad del Poder Legislativo y deslegitima el desempeño de sus funciones representativas, normativas y fiscalizadoras. En este contexto, el Legislativo difícilmente podrá cumplir con su papel de vigilar el ejercicio ilimitado de poder de los actores públicos cuando sobre él se cierne la sombra de una posible desconfianza. Los resultados de este trabajo permiten sostener que incorporar mecanismos que limiten o penalicen la compra de votos y las prácticas clientelares, fomentar el papel proactivo fiscalizador del Poder Legislativo, y garantizar la independencia de la judicatura, incidirán en la reducción de la percepción de corrupción legislativa en América Latina.

\section{Bibliografía}

Acemoglu, D. y Robinson, J. (2012). Why nations fail. The origins of power, prosperity and poverty. New York: Crown Publisher. Disponible en: https://doi.org/10.1355/ae29-2j.

Adsera, A., Boix, C. y Payne, M. (2003). Are you being served? Political eccountability and the quality of government. Journal of Law, Economics and Organization, 19, (2), 445-490. Disponible en: https://doi.org/10.1093/jleo/ewg017.

Alcántara, M. (2004). ¿Instituciones o maquinas ideológicas? Origen, programa y organizaciones de los partidos latinoamericanos. Barcelona: Institut de Ciències Polítiques i Socials.

Alcántara, M. (dir.) (1994-2017). Proyecto Élites Parlamentarias Latinoamericanas (PELA). Universidad de Salamanca. Disponible en: https://oir.org.es/pela/.

Barreda, M. y Ruiz, L. (2014). Organismos electorales y calidad de la democracia en América Latina. Lima: Junta Nacional Electoral.

Barrientos, F. (2010). Confianza en las elecciones y el rol de los organismos electorales en América Latina. Revista de Derecho Electoral, 10, 1-35.

Benito, A. B. (2017). El diputado conseguidor. Representación política particularista en el Congreso de la República Dominicana, 1998-2010. Revista Española de Ciencia Politica, 44, 151-179. Disponible en: https://doi.org/10.21308/recp.44.06.

Bowler, S., Farrell, D. y Katz, R. (1999). Party Discipline and Parliamentary Government. Ohio: Ohio State University Press. 
Cañete Alonso, R. M. (2015). Privilegios que niegan derechos. Desigualdad extrema y secuestro de la democracia en América Latina y El Caribe. Oxford: Oxfam International. Disponible en: https://bit.ly/2Pmu5gX.

Carey, J. y Shugart, M. (1994). Incentives to Cultivate a Personal Vote. Electoral Studies, 14 (4), 417-439. Disponible en: https://doi.org/10.1016/0261-3794(94)00035-2.

Carlin, R. y Love, G. (2015). Who is the Latin American Voter? En R. Carlin, M. Singer y E. Zechmeister (eds.). The Latin American Voter: Pursuing Representation and Accountability in Challenging Context (pp. 31-60). Ann Arbor: University of Michigan Press. Disponible en: https://doi.org/10.3998/mpub.8402589.

Casas, K. y Zovatto, D. (2011). Para llegar a tiempo: apuntes sobre la regulación del financiamiento político en América Latina. Revista de Derecho Electoral, 12, 1-58. Disponible en: https://doi.org/10.22201/iij.24487910e.2012.2.9976.

Coppedge, M. J. et al. (2018). V-Dem [Country-Year/Country-Date] Dataset v8. Varieties of Democracy (V-Dem) Project. Disponible en: https://bit.ly/2NWI2Sc.

Cox, G., Morgenstern, S. y Wolfson, L. (2001). Legislaturas reactivas y presidentes proactivos en América Latina. Desarrollo Económico, 41 (163), 373-393. Disponible en: https:// doi.org/10.2307/3456006.

Ferraro, A. (2009). Reinventando el Estado. Por una Administración pública democrática y profesional en Iberoamérica. Madrid: Instituto Nacional de Administración Pública.

Fish, S. M. (2006). Stronger Legislatures, stronger democracies. Journal of Democracy, 1 (7), 5-20. Disponible en: https://doi.org/10.1353/jod.2006.0008.

Fisman R. y Gatti, R. (2002). Decentralization and corruption: evidence across countries. Journal of Public Economy, 83, 325-345. Disponible en: https://doi.org/10.1016/ S0047-2727(00)00158-4.

Freidenberg, F. y Alcántara, M. (2009). Selección de candidatos, politica partidista y rendimiento democrático. México: Tribunal Electoral del Distrito Federal.

García Montero, M. (2009). Presidentes y Parlamentos. ¿Quién controla la actividad legislativa en América Latina? Madrid: Centro de Investigaciones Sociológicas.

Gutmann, J., Padovano, F. y Voigt, S. (2015). Perception vs. Experience: Explaining differences in corruption measures using microdata. Social Sciences Research Network Electronic Journal, 1, 1-29. Disponible en: https://dx.doi.org/10.2139/ssrn.2659349.

Kaufmann, D. (2005). Back to Basics. Ten Myths about Governance and Corruption. Finance and Development, FMI, 42 (3), 81-98. Disponible en: https://dx.doi.org/10.2139/ssrn.829244.

Kitschelt, H. et al. (2010). Latin American Party System. Cambridge: Cambridge University Press. Disponible en: https://doi.org/10.1017/CBO9780511750311.

Kitschelt, H. y Wilkinson, S. (2007). Patrons, Clients and Policies. Cambridge University Press. Disponible en: https://doi.org/10.1017/CBO9780511585869.

Krehbiel, K. (2004). Legislative organization. Journal of Economic Perspectives, 18 (1), 113-128. Disponible en: https://doi.org/10.1257/089533004773563467.

Langston, J. (2008). Legislative recruitment in Mexico. En P. Siavelis y S. Morgenstern (eds.). Pathways to Power. Political Recruitment and Candidate Selection in Latin America (p. 143-163). Pennsylvania: Pennsylvania University Press.

Levi, M. (1996). Social and Unsocial Capital. Politics and Society, 24, 45-55. Disponible en: https://doi.org/10.1177\%2F0032329296024001005. 
Levitsky, S. (1998). Institutionalization and Peronism. The Case, the Concept, and The Case of Unpacking the Concept. Party Politics, 4 (1), 77-92. Disponible en: https://doi.org/ $10.1177 \% 2 F 1354068898004001004$.

Lijphart, A. (1991). Foreword: Cameral change and institutional conservatism. En L. D. Logley y D. M. Olson (eds). Two into One: The Politics of National Legislative Cameral Change (p. 9). Boulder: Westview Press.

Mainwaring, S. y Scully, T. (1995). La institucionalización de los sistemas de partidos en América Latina. Revista de Ciencia Política, 17 (1), 63-101.

Mainwaring, S. y Torcal, M. (2005). La institucionalización de los sistemas de partidos en América Latina. Revista América Latina Hoy, 41 (10), 141-173.

Máiz, R. (2003). Jama, caleta y camello: la corrupción como mecanismo de autorrefuerzo del clientelismo político. Revista Mexicana de Sociología, 65 (1), 3-39. Disponible en: https://doi.org/10.2307/3541514.

Manzetti, L. y Rosas, G. (2015). Corruption and the Latin American Voter. En R. Carlin, M. Singer y E. Zechmeister (ed). The Latin American Voter: Pursuing Representation and Accountability in Challenging Context (pp. 300-323). Ann Arbor: University of Michigan Press.

March, J. y Olsen, J. (1984). The New Institutionalism: Organizational Factors in Political Life. American Political Science Review, 78, 734-745. Disponible en: https://doi. org/10.2307/1961840.

Martí, S. (2018). El régimen patrimonial de Nicaragua y las elecciones de 2016. En M. Alcántara y L. Tagina (eds.). Elecciones y partidos en América Latina en el cambio de ciclo (pp. 303-326). Madrid: Centro de Investigaciones Sociológicas.

Martínez Barahona, E. (2010). Judges as Invited Actors in the Political Arena. The Cases of Costa Rica and Guatemala. Mexican Law Review, 3 (1), 3-24.

Martínez Rosón, M. (2011). La selección de candidatos parlamentarios en Costa Rica, Honduras y El Salvador 2006-2010. Anuario de Estudios Centroamericanos, 37, 13-51.

Mauro, P. (1995). Corruption and growth. Quarterly Journal of Economics, 110 (3), 681-712. Disponible en: https://doi.org/10.2307/2946696.

Ministerio de Salud Pública (MSP) (2011). Estadisticas. Disponible en: https://bit.ly/3fgW7VE.

Moriconi, M. (2011). ¿Ilegalidad justificada? Clientelismo controlado en la Administración chilena. Perfiles Latinoamericanos, 38, 227-248.

Morlino, L. (1995). Consolidation and party government in Southern Europe. International Political Science Review, 16 (2), 145-167. Disponible en: https://doi.org/10.1177\% 2F019251219501600203.

Neshkova, M. y Kostadinova, T. (2012). The Effectiveness of Administrative Reform in New Democracies. Public Administration Review, 72, 324-333. Disponible en: https://doi. org/10.1111/j.1540-6210.2011.02483.x.

North, D. C. (1993). Instituciones, cambio institucional y desempeño económico. México: Fondo de Cultura Económica.

O’Donnell, G. (2004). Accountability horizontal. La institucionalización legal de la desconfianza política. Revista Española de Ciencia Politica, 11, 11-31.

Oliveros, V. y Schuster, C. (2018). Merit, Tenure and Bureaucratic Behavior: Evidence from a Conjoint Experiment in the Dominican Republic. Comparative Political Studies, 51 (6), 759-792. Disponible en: https://doi.org/10.1177\%2F0010414017710268. 
Otero, P. y Rodríguez-Zepeda, J. A. (2015). El papel de la ideología en los partidos latinoamericanos. Revista Latinoamericana de Politica Comparada, 9, 71-95.

Owen, J. E. (2003). Explaining Party Cohesion and Discipline in Democratic Legislatures: Purposiveness and Contexts. The Journal of Legislatives Studies, 9 (4), 12-40. Disponible en: https://doi.org/10.1080/1357233042000306236.

Ozbudun, E. (1970). Party Cohesion in Western Democracies. A Causal Analysis. California: Sage. Panebianco, A. (1997). Modelos de partidos. Madrid: Alianza Editorial.

Papakostas, A. (2001). Why is there no clientelism in Scandinavia? A comparison of Swedish and Greek sequence of development. En S. Piattoni (ed). Clientelism, Interests, and Democratic Representation: The European Experience in Historical and Comparative Perspective (pp. 31-53). New York: Cambridge University Press. Disponible en: https://doi. org/10.1017/CBO9781139175340.003.

Payne, M., Zovatto, D., Carillo, F. y Allamand, A. (2002). Democracies in Development. Politics and Reform in Latin America. Washington: Inter-American Development Bank.

Pérez Liñán, A. (2011). Democracia y defensa constitucional en América Latina. Politaj: Revista de Ciencia Politica, 2 (2), 56-67.

Picado, H. (2006). Calidad de las elecciones en Latinoamérica. La independencia formal de los Tribunales Electorales en México, Centroamérica y Panamá. En XII Encuentro de Latinoamericanistas Españoles. Santander: CEEI.

Rahat, G. y Hazan, R. (2001). Candidate Selection Methods: An analytical framework. Party Politics, 7 (3), 297-322. Disponible en: https://doi.org/10.1177\%2F1354068801007003003.

Rauch, J. y Evans, P. (2000). Bureacratic Structure and Bureaucratic Performance in Less Developed Countries. Journal of Public Economics, 75, 49-71. Disponible en: https:// doi.org/10.1016/S0047-2727(99)00044-4.

Rose-Ackerman, S. (1999). Corruption and Government: Causes, Consequences, and Reform. Cambridge: University Press. Disponible en: https://doi.org/10.1017/CBO97811391 75098.

Sánchez Medero, G. (2018). Transparencia y regeneración democrática en los partidos políticos. En J. M. Canales, B. Aldeguer, F. Querol y S. Castel (coords). Estrategias para la calidady la regeneración de la democracia (pp. 119-134). Alicante: Universidad de Alicante.

Sinclair, B. (2003). Legislative Cohesion and Presidential Policy Success. The Journal of Legislatives Studies, 9 (4), 41-56. Disponible en: https://doi.org/10.1080/13572330420003 06245.

Solís, D. y Cortez, J. (2019). ¿Qué intereses se representan en el Congreso? Legisladores mexicanos con antecedentes en grupos de interés, 2006-2015. Perfiles Latinoamericanos, 27 (3), 1-26. Disponible en: https://doi.org/10.18504/pl2753-013-2019.

Thompson, J. (2014). Tendencias en torno a la estructura y competencias de los organismos electorales en América Latina. En M. Barreda Díez y L. Ruiz Rodríguez (eds.). Organismos electorales y calidad de la democracia en América Latina. Lima: Junta Nacional Electoral.

Transparency International (2018). Corruption Perceptions Index (CPI). Disponible en: https:// www.transparency.org/cpi2018.

Treisman, D. (2000). The causes of corruption: a cross-national study. Journal of Public Economy, 76 (3), 399-458. Disponible en: https://doi.org/10.1016/S0047-2727(99)00092-4. 
Treisman, D. (2007). What have we learned about the causes of corruption from ten years of cross-national empirical research? Annual Review of Political Science, 10, 211-244. Disponible en: https://doi.org/10.1146/annurev.polisci.10.081205.095418.

Van Zyl Smit, J. (2016). Judicial Appointments in Latin America: The Implications of Tenure and Appointment Processes. London: Bingham Centre for the Rule of Law.

Villoria, M. (2018). La transparencia, la imparcialidad y la calidad de la democracia. Dilemata, 27,1-16.

Villoria, M. y Jiménez, F. (2012). La corrupción en España (2004-2010): datos, percepción y efectos. Revista Española de Investigaciones Sociológicas, 138, 109-134. Disponible en: https://doi.org/10.5477/cis/reis.138.109.

Ware, A. (1996). Political Parties and Party Systems. New York: Oxford University Press.

Weber, C. (2008). How much do perceptions of corruption really tell us? Economics, 2 (3), 1-56. Disponible en: http://dx.doi.org/10.5018/economics-ejournal.ja.2008-3.

World Economic Forum (WEF) (2016). The Global Competitiveness Report. En K. Schwab (ed.). Executive Opinion Survey. Geneva: World Economic Forum.

World Bank (2017). Worldwide Governance Indicators (WGI). Disponible en: https://info. worldbank.org/governance/wgi/.

Wuhs, S. T. (2010). From the Boarddroom to the Chamber: Business Interests and Party Politics in Mexico. Journal of Politics in Latin America, 2 (1), 107-130. Disponible en: https://doi.org/10.1177\%2F1866802X1000200105.

Zovatto, D. (2017). El financiamiento político en América Latina. Studia Politicae, 40, 7-52. 


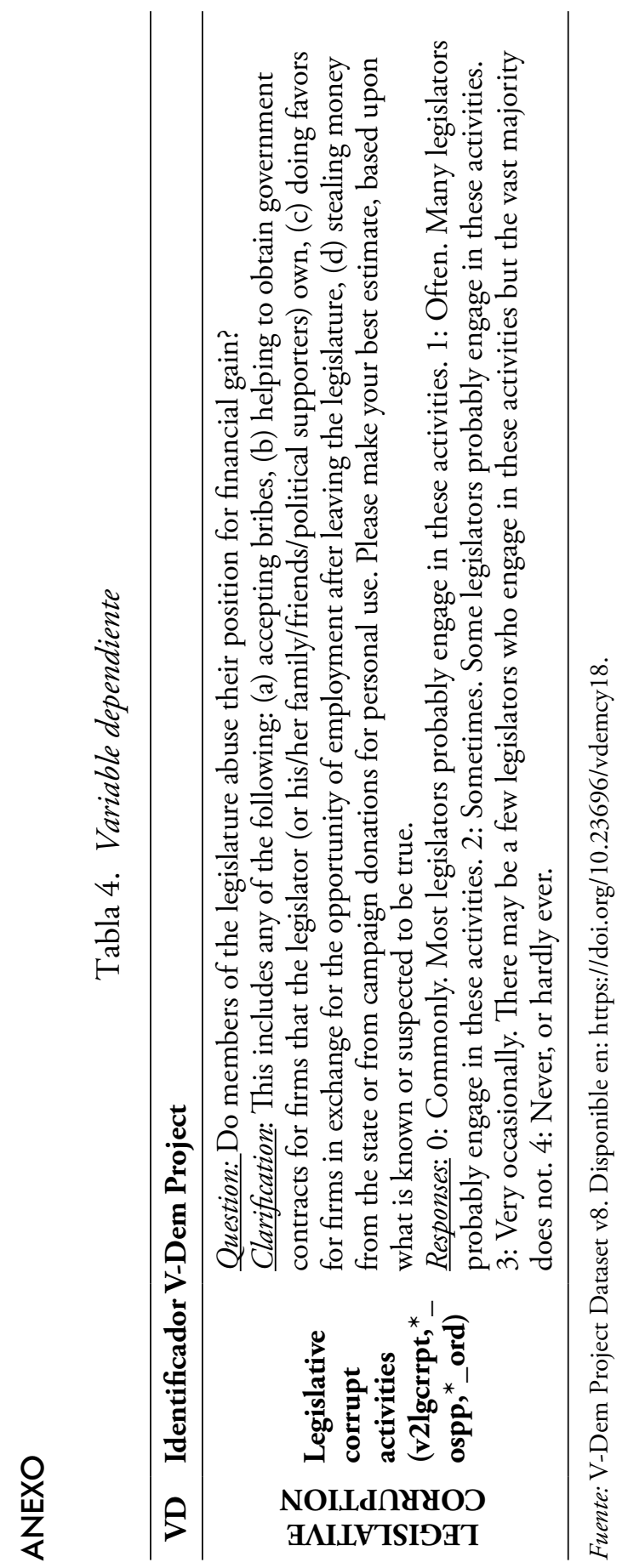




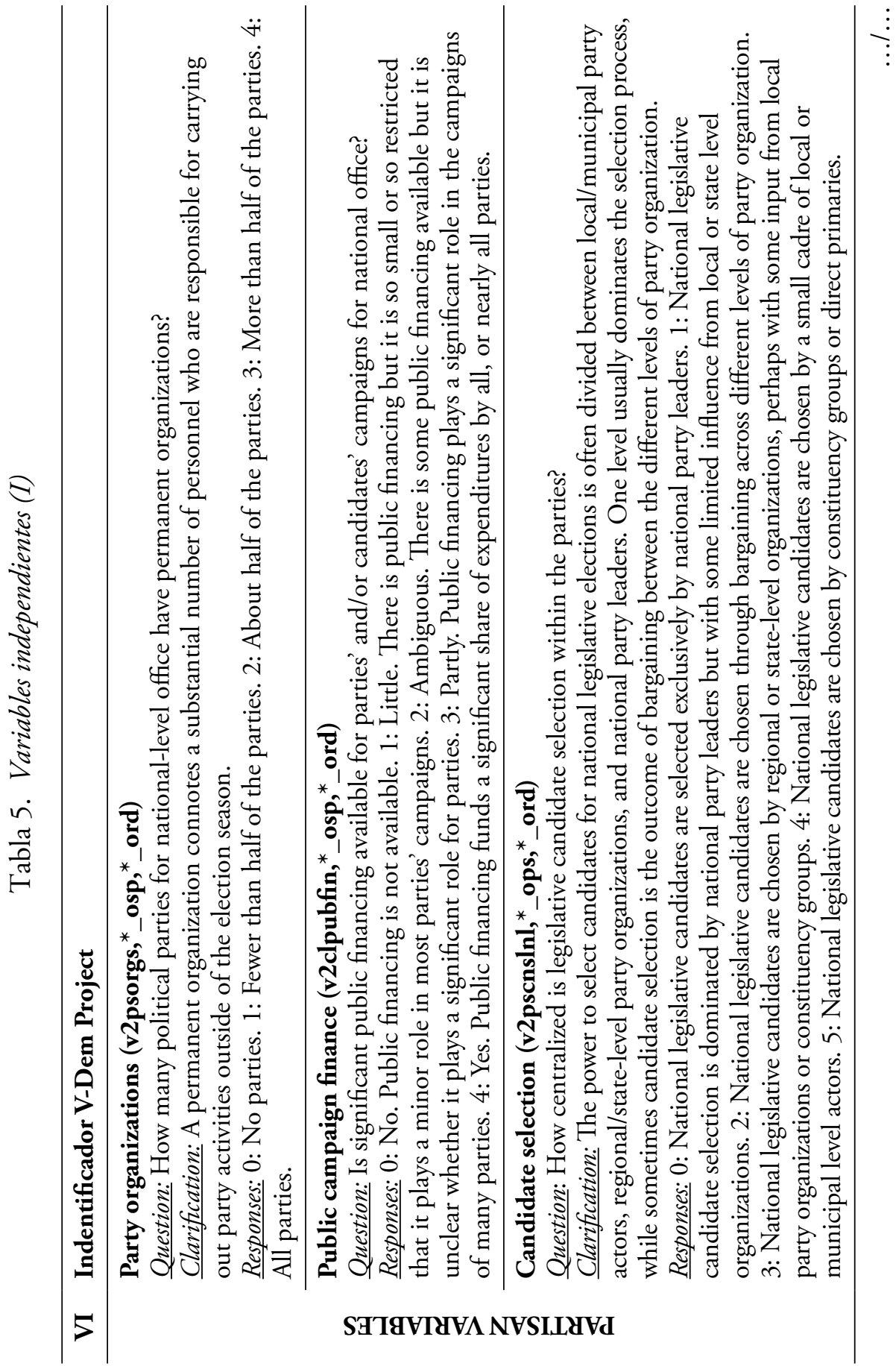




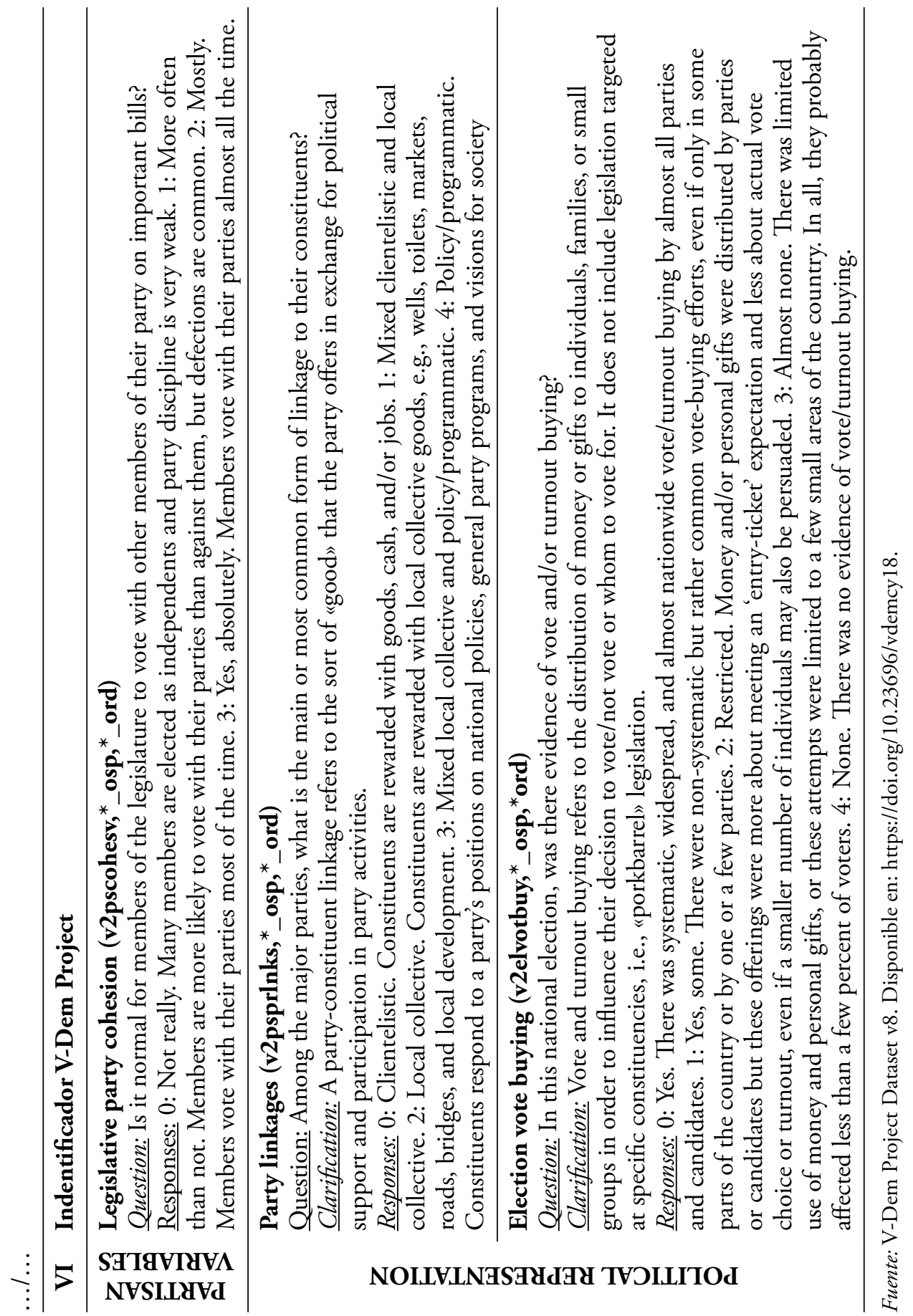




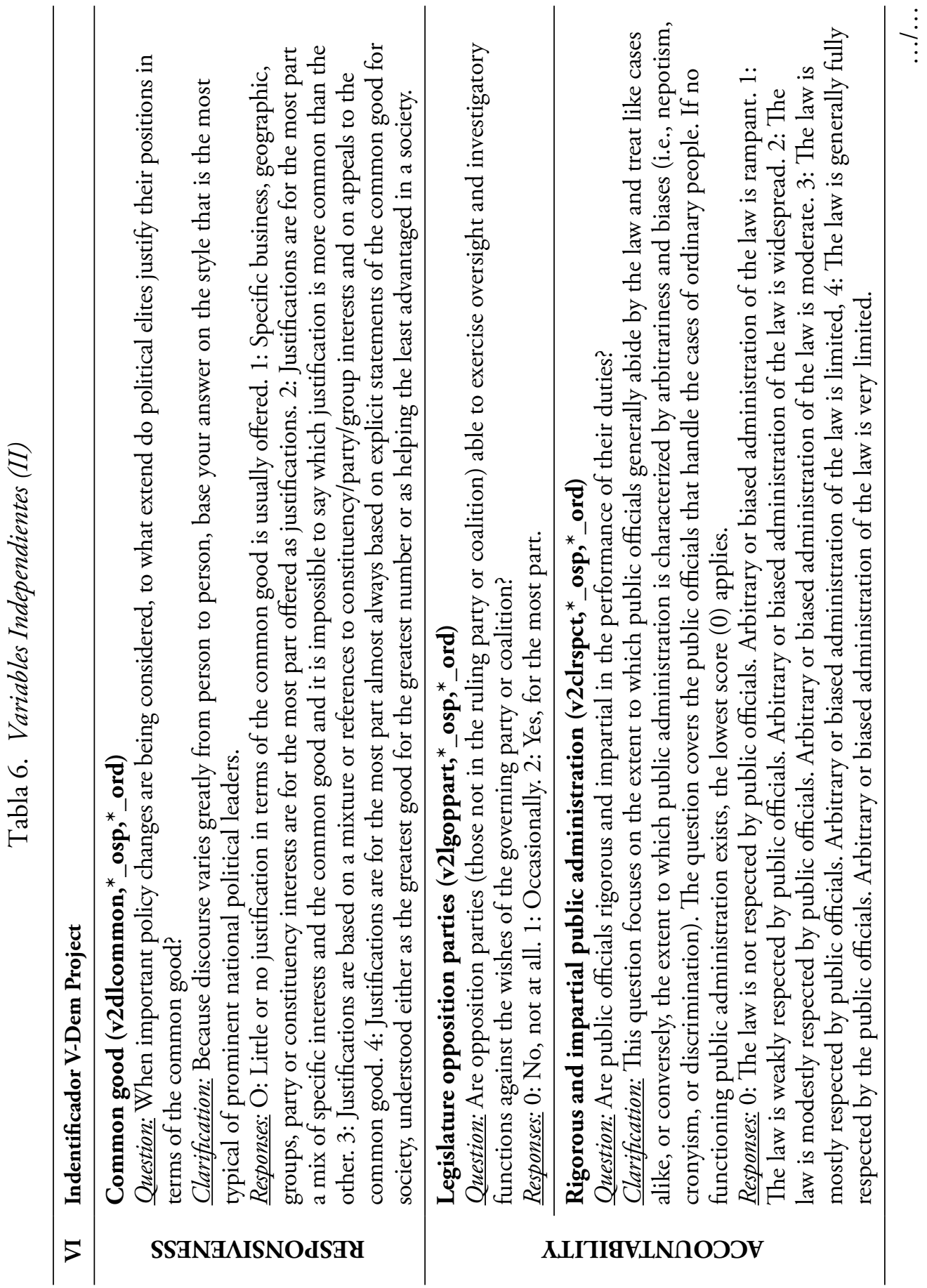




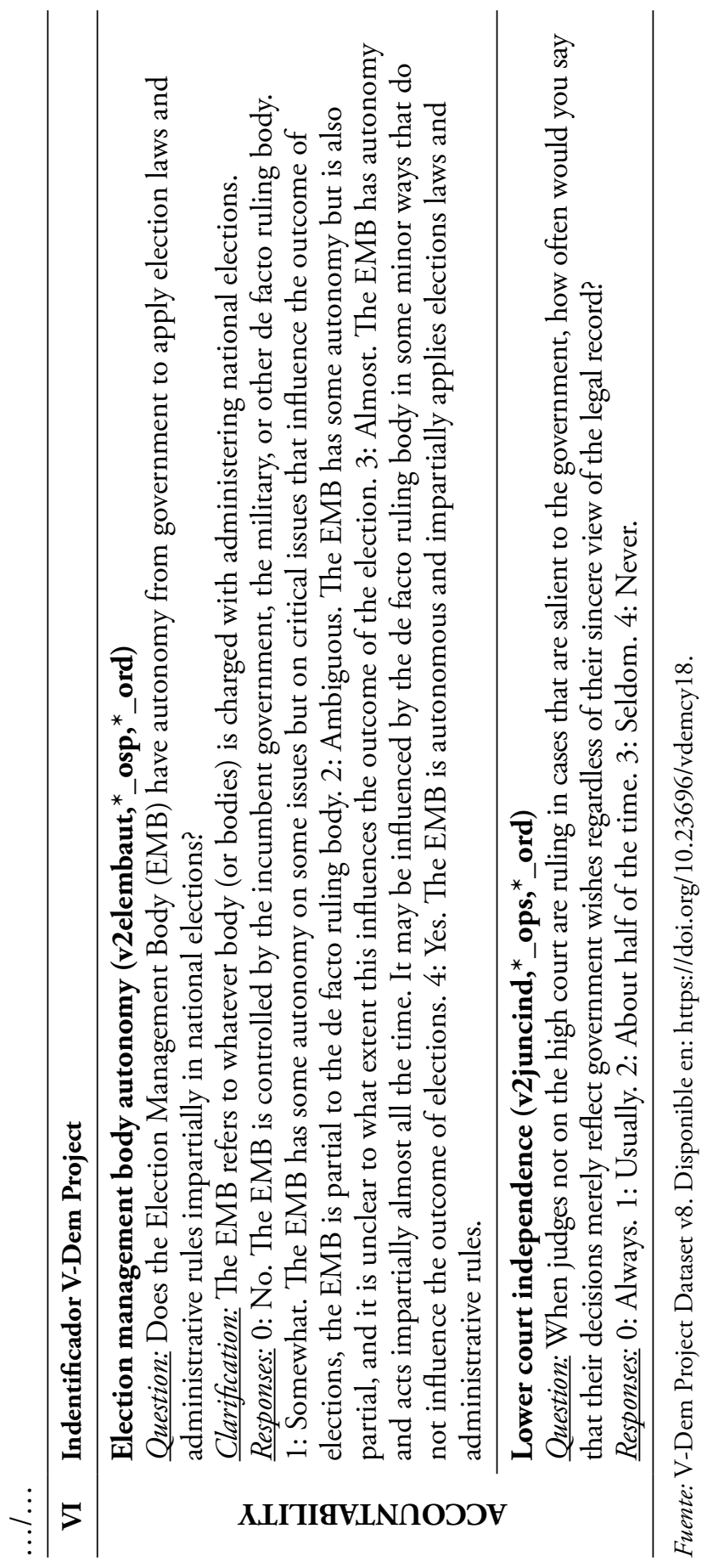




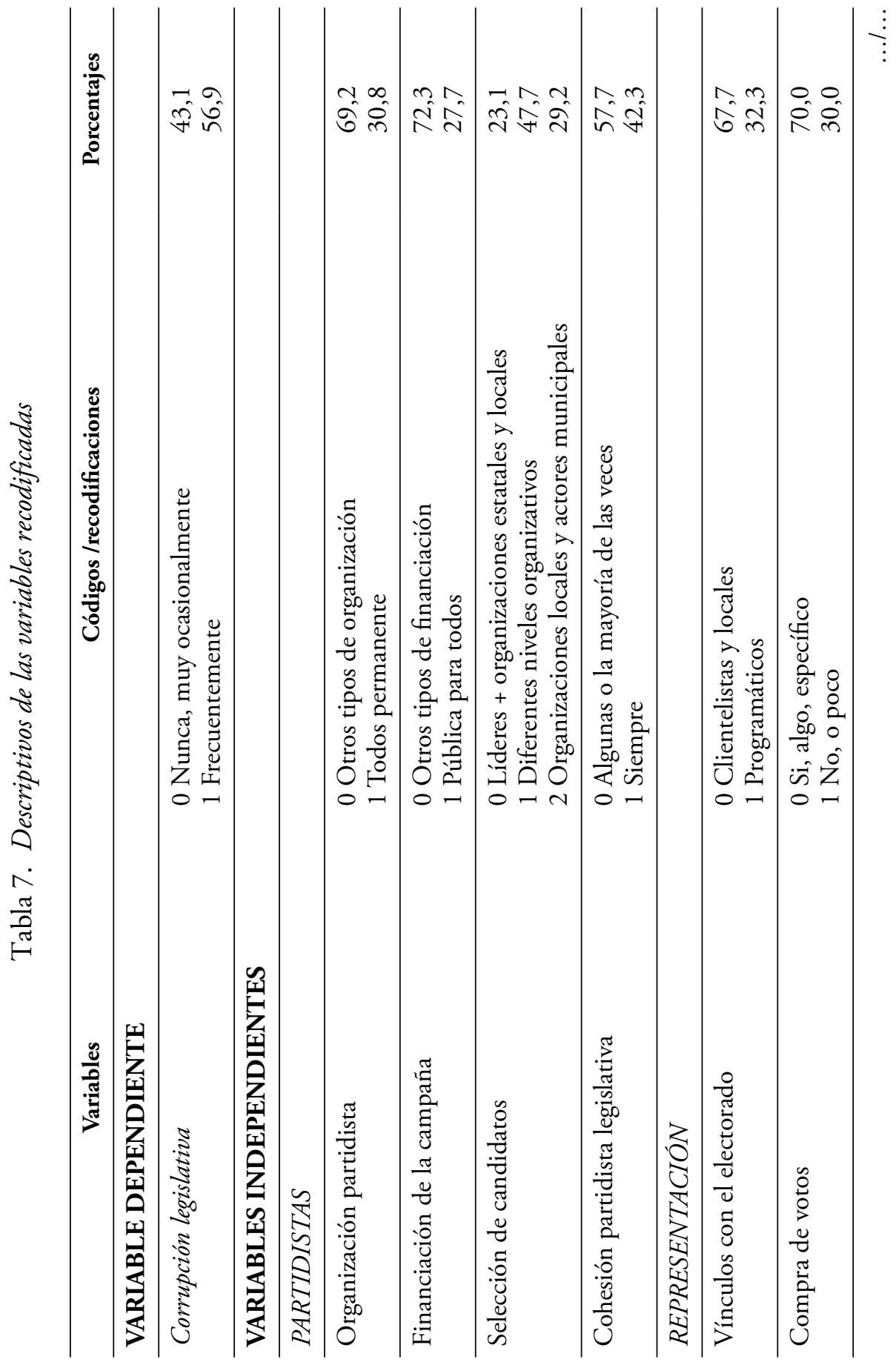




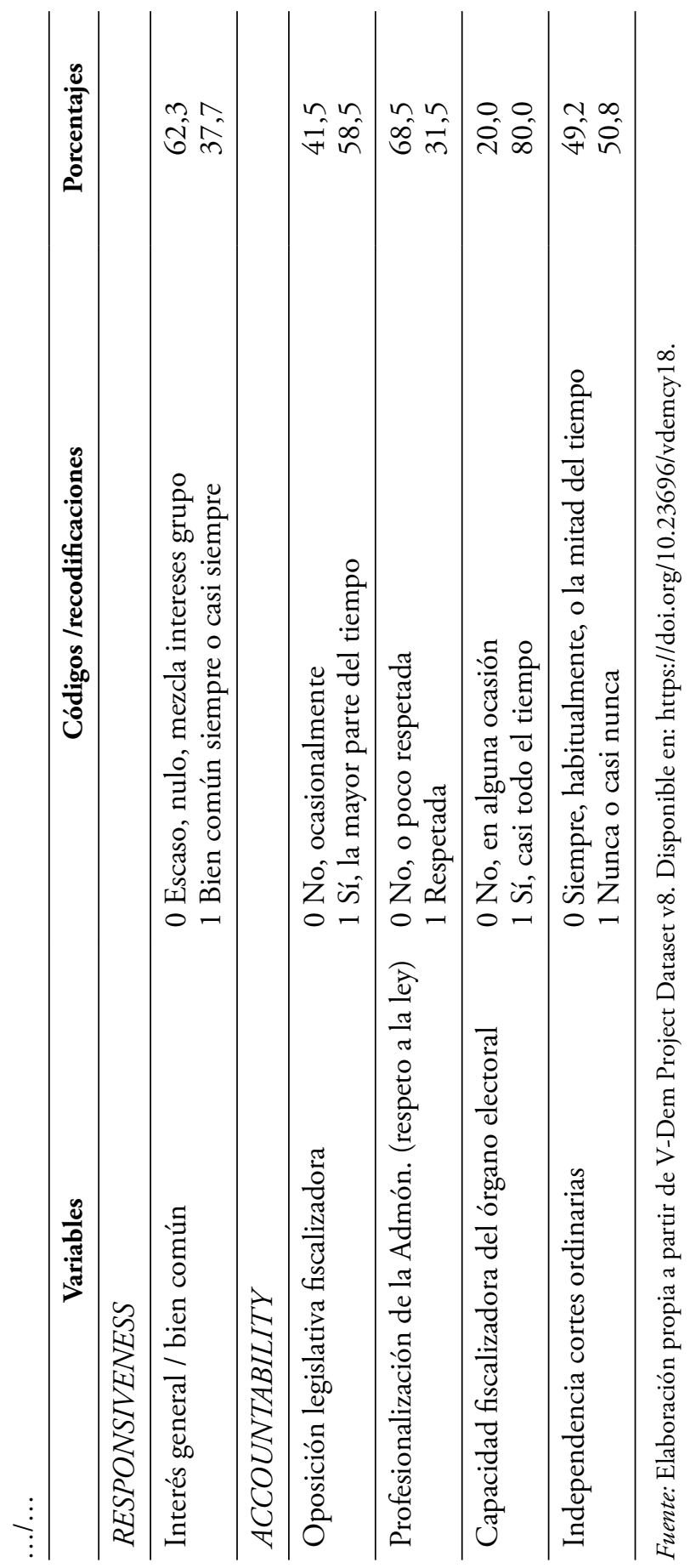

